\title{
Hydrogen Sulfide Stimulates Wheat Grain Germination and Counteracts the Effect of Oxidative Damage Caused by Salinity Stress
}

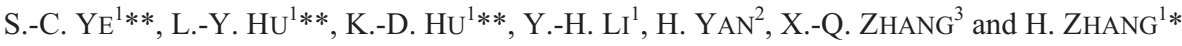 \\ ${ }^{1}$ School of Biotechnology and Food Engineering, Hefei University of Technology, \\ Hefei 230009, PR China \\ ${ }^{2}$ College of Chemical and Environmental Engineering, Harbin University of Science and Technology; \\ Key Laboratory of Green Chemical Technology of College of Heilongjiang Province, \\ Harbin 150080, PR China \\ ${ }^{3}$ Anhui Academy of Agricultural Sciences, Hefei 230031, PR China \\ (Received 21 April 2014; Accepted 2 July 2014; \\ Communicated by G.V. Horváth)
}

\begin{abstract}
Hydrogen sulfide $\left(\mathrm{H}_{2} \mathrm{~S}\right)$ has been recently found to be a gaseous signaling molecule in plants. In this work, we studied the role of $\mathrm{H}_{2} \mathrm{~S}$ in alleviating salinity stress during wheat grain germination (Triticum aestivum L. Yangmai 158). Pretreatment with $\mathrm{NaHS}$, a $\mathrm{H}_{2} \mathrm{~S}$ donor, during wheat grain imbibition, could significantly attenuate the inhibitory effect of salinity stress on wheat germination. NaHS-pretreated grain showed higher amylase and esterase activities than water control. NaHS pretreatment differentially stimulated the activities of catalase (CAT), guaiacol peroxidase (POD) and ascorbate peroxidase (APX), decreased the level of malondialdehyde (MDA) and reduced $\mathrm{NaCl}$-induced changes in plasma membrane integrity in the radicle tips of seedlings compared with water control. We conclude that $\mathrm{H}_{2} \mathrm{~S}$ plays an important role in protecting wheat grain from oxidative damage induced by salinity stress.
\end{abstract}

Keywords: antioxidant enzymes, hydrogen sulfide, salinity stress, wheat (Triticum aestivum) grain germination

\section{Introduction}

High salinity can inhibit cereal grain germination by affecting diverse physiological processes including osmotic effects, specific-ion toxicity and nutritional disorders (Zhu 2001 ; 2002). Salt stress can also cause oxidative stress due to the production of reactive oxygen species (ROS) such as the superoxide radical, hydrogen peroxide, singlet oxygen and hydroxyl radicals (Leshem et al. 2007). Excessive ROS can result in oxidative damage to lipids, proteins and DNA. However, plants have developed both enzymatic and non-enzymatic mechanisms to scavenge the overproduction of ROS. Antioxidant en-

\footnotetext{
* Corresponding author; E-mail: hzhanglab@gmail.com
}

** These authors contributed equally to this work. 
zymes such as superoxide dismutase (SOD), catalase (CAT), ascorbate peroxidase (APX) and guaiacol peroxidase (POD) are mobilized for scavenging ROS, thereby avoiding the oxidative stress caused by salt stress (Sekmen et al. 2007).

Hydrogen sulfide $\left(\mathrm{H}_{2} \mathrm{~S}\right)$, like nitric oxide $(\mathrm{NO})$ and carbon monoxide $(\mathrm{CO})$ is a gaseous transmitter in mammalian cells (Wang 2012). Similar to NO and $\mathrm{CO}, \mathrm{H}_{2} \mathrm{~S}$ at low concentrations participates in various biological processes in animal cells (Yang et al. 2008; Wang 2012). In plants, $\mathrm{H}_{2} \mathrm{~S}$ can be produced from cysteine via a reversible O-acetylserine (thiol) lyase (OAS-TL) reaction and some desulfhydrases (Rausch and Wachter 2005). L-cysteine desulfhydrase expression can be induced upon pathogen attack, suggesting a role of $\mathrm{H}_{2} \mathrm{~S}$ in pathogen attack (Bloem et al. 2005).

$\mathrm{H}_{2} \mathrm{~S}$ has been implicated in various physiological processes in plants such as adventitious root organogenesis, stomatal movement, postharvest senescence of fruits and vegetables, flower senescence, and cell autophagy (Zhang et al. 2009; García-Mata and Lamattina 2010; Zhang et al. 2011; Álvarez et al. 2012; Hu et al. 2012; Gao et al. 2013; Lisjak et al. 2013). Evidence also shows that $\mathrm{H}_{2} \mathrm{~S}$ counteracts multiple abiotic stresses including copper, aluminum, salinity and drought stresses, by activating endogenous antioxidant systems (Zhang et al. 2008; Zhang et al. 2010; Jin et al. 2011; Wang et al. 2012; Jin et al. 2013). However, whether $\mathrm{H}_{2} \mathrm{~S}$ participates in the antioxidant response to salt stress in wheat is still unknown. In this study, the effects of $\mathrm{H}_{2} \mathrm{~S}$ pretreatment on wheat grain germination under salinity stress are described and we describe an important role of $\mathrm{H}_{2} \mathrm{~S}$ in protecting wheat grain from oxidative damage induced by salinity stress.

\section{Materials and Methods}

\section{Materials and treatments}

Wheat grain used in this research (Triticum aestivum L. cv. Yangmai 158) were supplied by the Jiangsu Academy of Agricultural Sciences, Jiangsu Province, China. NaHS (sodium hydrosulfide, Sigma) was used as the $\mathrm{H}_{2} \mathrm{~S}$ donor (Zhang et al. 2008). Wheat grain were sterilized with $0.1 \% \mathrm{HgCl}_{2}$ (w/v) for $3 \mathrm{~min}$ and washed extensively with distilled water, and dried with filter paper. To investigate the inhibitory effect of salinity on wheat grain germination, grain were allocated randomly in Petri dishes $(9.0 \mathrm{~cm}$ diameter $\times$ $1.2 \mathrm{~cm}$ depth, 50 grain per dish) at $28^{\circ} \mathrm{C}$ and treated with $0,0.08,0.16,0.24,0.32,0.4 \mathrm{M}$ $\mathrm{NaCl}$ for $48 \mathrm{~h}$. Germination percentage was calculated as a standard that the length of the coleoptile or radicle exceeds $50 \%$ of grain length. The length of coleoptiles and radicles and the number of radicles were recorded. Preliminary experiments showed that $0.16 \mathrm{M}$ $\mathrm{NaCl}$ caused obvious inhibition of wheat grain germination and this concentration was chosen for further experiments.

To explore possible effect of $\mathrm{H}_{2} \mathrm{~S}$ on salinity-induced inhibition of grain germination, wheat grain were pretreated with $0.0,0.6,1.2,1.8,2.4$ or $3.0 \mathrm{mM} \mathrm{NaHS}$ for $12 \mathrm{~h}$, and subsequently subjected to $0.16 \mathrm{M} \mathrm{NaCl}$ for a further $48 \mathrm{~h}$. All solutions were changed every $12 \mathrm{~h}$. The optimal NaHS concentration that alleviated the germination of wheat grain under salinity stress was found by calculating germination percentage. 
Grain were pretreated by water (CK) or the optimal concentration of $1.2 \mathrm{mM} \mathrm{NaHS}$ for $12 \mathrm{~h}$ (pretreatment time), and then exposed to $0.16 \mathrm{M} \mathrm{NaCl}$ stress for further $48 \mathrm{~h}$ (from 0 to $48 \mathrm{~h}$ of stress time). Germinating grain $(0.5 \mathrm{~g})$ at different time points were randomly sampled for further analysis. For each treatment, 50 grains were used and the germination percentage represented the mean number of germinated grain from three independent experiments.

\section{Electrophoretic analysis of amylase and esterase}

Wheat grain $(0.5 \mathrm{~g})$ were homogenized in $5 \mathrm{~mL}$ ice-cold phosphate buffer $(200 \mathrm{mM}$, $\mathrm{pH} 8.3$ ) and the homogenate was centrifuged at $12,000 \mathrm{~g}$ for $30 \mathrm{~min}$. Then the supernatants were used for electrophoretic analysis of amylase and esterase. Electrophoretic analysis of amylase and esterase were carried out according to the methods described by Zhang et al. (2005) and Deising et al. (1992), respectively.

\section{Assays of CAT, APX and POD activities}

Activities of catalase (CAT, EC 1.11.1.6), ascorbate peroxidase (APX, EC 1.11.1.11), and guaiacol peroxidase (POD, EC 1.11.1.7) were assayed according to García-Limones et al. (2002).

\section{Analyses of cell plasma membrane integrity in radicle tips}

To study salinity-induced loss of plasma membrane integrity in the radicle tips of wheat, seedlings radicle tips were stained with Evans blue according to the method described by Yamamoto et al. (2001). For water control, intact wheat grain were cultured in water for $72 \mathrm{~h}(\mathrm{CK})$. For $\mathrm{NaCl}$ stress $(\mathrm{NaCl})$, wheat grain were cultured in water for $36 \mathrm{~h}$, then subjected to $0.16 \mathrm{M} \mathrm{NaCl}$ for further $36 \mathrm{~h}$. Grain cultured in water for $24 \mathrm{~h}$ and immersed in $1.4 \mathrm{mM}$ NaHS for $12 \mathrm{~h}$ were then divided into two equal groups and transferred to water (NaHS) or $0.16 \mathrm{M} \mathrm{NaCl}$ stress for $36 \mathrm{~h}(\mathrm{NaCl}+\mathrm{NaHS})$, respectively. Intact radicles were washed with $0.5 \mathrm{mM} \mathrm{CaCl}_{2}(\mathrm{pH}$ 5.6) solution several times, dried with filter papers and immediately immersed in $0.1 \mathrm{mM} \mathrm{CaCl}_{2}$ (pH 5.6) solution containing $0.025 \%$ (w/v) Evans blue for $1 \mathrm{~h}$. Stained radicles were then washed three time with sufficient volume of $0.1 \mathrm{mM} \mathrm{CaCl}_{2}$ (pH 5.6) solution and photographed.

\section{Determination of MDA content}

The content of MDA was determined by a procedure based on the method of Wang and Yang (2005).

\section{Measurement of reducing sugar in germinating wheat grain}

Wheat grain $(0.5 \mathrm{~g})$ were homogenized in $5 \mathrm{~mL}$ ice-cold phosphate buffer $(200 \mathrm{mM}, \mathrm{pH}$ 8.3 ) and the homogenate was centrifuged at $12,000 \mathrm{~g}$ for $30 \mathrm{~min}$. The content of reducing sugar was assayed according to method of DNS spectrophotometry. 


\section{Statistical analysis}

Significances were tested by one-way ANOVA, and the results are expressed as the mean values $\pm \mathrm{SD}$. Each experiment was repeated for three times. Fisher's least significant differences (LSD) were calculated following a significant $(p<0.01$ or $p<0.05) t$-test.

\section{Results}

Inhibitory effect of salinity on the germination of wheat grain

As shown in Fig. S1* and Table $\mathrm{S} 1$, with increasing concentrations of $\mathrm{NaCl}$, germination percentage wheat grain decreased gradually and the germination was totally inhibited with $0.4 \mathrm{M} \mathrm{NaCl}$ stress. At $0.16 \mathrm{M} \mathrm{NaCl}$, germination was dramatically reduced to $24 \% \mathrm{com}$ pared with $85 \%$ for water control (Table S1, Fig. S1). For instance, coleoptile length at $0.08 \mathrm{M} \mathrm{NaCl}$ was almost halved $(0.9 \mathrm{~cm})$ in contrast to water control $(1.6 \mathrm{~cm})$, indicating high sensitivity of wheat to salinity stress. Meanwhile, radicle growth was also stunted upon $0.08 \mathrm{M} \mathrm{NaCl}$ stress.

Protective roles of NaHS pretreatment on the germination of wheat grain subjected to salinity stress

NaHS solution was used as an $\mathrm{H}_{2} \mathrm{~S}$ donor to study the effect of $\mathrm{H}_{2} \mathrm{~S}$ on germinating wheat grain subjected to $0.16 \mathrm{M} \mathrm{NaCl}$ stress. Wheat grains were pretreated for $12 \mathrm{~h}$ with different NaHS concentrations $(0,0.6,1.2,1.8,2.4,3 \mathrm{mM})$, then exposed to $0.16 \mathrm{M} \mathrm{NaCl}$ stress. The germination percentage, coleoptile length, radicle number and length gradually increased to a maximum at $1.2 \mathrm{mM}$ NaHS (Table 1, Fig. S2). However, concentrations of NaHS higher than $1.2 \mathrm{mM}$ conferred no additional protection to wheat grain against $\mathrm{NaCl}$. Thus $1.2 \mathrm{mM}$ NaHS was selected for subsequent experiments.

Table 1. Effects of NaHS pretreatment on wheat grain germination under $\mathrm{NaCl}$ stress

\begin{tabular}{lcccc}
\hline $\begin{array}{l}\text { Concentration } \\
\text { of NaHS }(\mathrm{mM})\end{array}$ & $\begin{array}{c}\text { Germination } \\
\text { percentage }(\%)\end{array}$ & $\begin{array}{c}\text { Length of } \\
\text { coleoptile }(\mathrm{cm})\end{array}$ & $\begin{array}{c}\text { Radicle number } \\
\text { (per grain) }\end{array}$ & $\begin{array}{c}\text { Length of } \\
\text { radicle }(\mathrm{cm})\end{array}$ \\
\hline 0.0 & $25 \pm 2 \mathrm{~d}$ & $0.3 \pm 0.1 \mathrm{a}$ & $0.74 \pm 0.08 \mathrm{~d}$ & $0.3 \pm 0.03 \mathrm{~b}$ \\
0.6 & $46 \pm 2 \mathrm{bc}$ & $0.4 \pm 0.1 \mathrm{a}$ & $1.38 \pm 0.06 \mathrm{c}$ & $0.4 \pm 0.07 \mathrm{a}$ \\
1.2 & $56 \pm 2 \mathrm{a}$ & $0.5 \pm 0.2 \mathrm{a}$ & $1.68 \pm 0.06 \mathrm{a}$ & $0.5 \pm 0.07 \mathrm{a}$ \\
1.8 & $45 \pm 1 \mathrm{c}$ & $0.4 \pm 0.2 \mathrm{a}$ & $1.36 \pm 0.04 \mathrm{c}$ & $0.4 \pm 0.05 \mathrm{a}$ \\
2.4 & $49 \pm 1 \mathrm{~b}$ & $0.3 \pm 0.1 \mathrm{a}$ & $1.48 \pm 0.04 \mathrm{~b}$ & $0.3 \pm 0.04 \mathrm{~b}$ \\
3.0 & $55 \pm 2 \mathrm{a}$ & $0.4 \pm 0.1 \mathrm{a}$ & $1.78 \pm 0.06 \mathrm{a}$ & $0.4 \pm 0.03 \mathrm{a}$ \\
\hline
\end{tabular}

Wheat grain were pretreated with $0.0,0.6,1.2,1.8,2.4$ and $3.0 \mathrm{mM} \mathrm{NaHS}$, respectively, for $12 \mathrm{~h}$, and subsequently subjected to $0.16 \mathrm{M} \mathrm{NaCl}$ for further $48 \mathrm{~h}$, and then the germination percentage was investigated. Values are the means $\pm S D(n=50)$. Different letters indicate significant difference $(p<0.05)$ between treatments.

* Further details about the Electronic Supplementary Material (ESM) can be found at the end of the article. 
Effects of NaHS on the activities of amylase and esterase in wheat grain under $\mathrm{NaCl}$ stress

To get an insight into the alleviating role of $\mathrm{H}_{2} \mathrm{~S}$ on salinity-stressed wheat grain germination, the activity of amylase and esterase were investigated by native polyacrylamide gel electrophoresis (PAGE). Figure 1A shows the changes of amylase activity in wheat grain during $48 \mathrm{~h}$ of $0.6 \mathrm{M} \mathrm{NaCl}$ stress, combined with $12 \mathrm{~h}$ water or NaHS pretreatment. During $12 \mathrm{~h}$ of water or NaHS pretreatment, NaHS induced significantly higher amylase activity. Under subsequent $\mathrm{NaCl}$ stress for $48 \mathrm{~h}$, amylase activity in NaHS-pretreated grain increased steadily, while that of the controls remained.

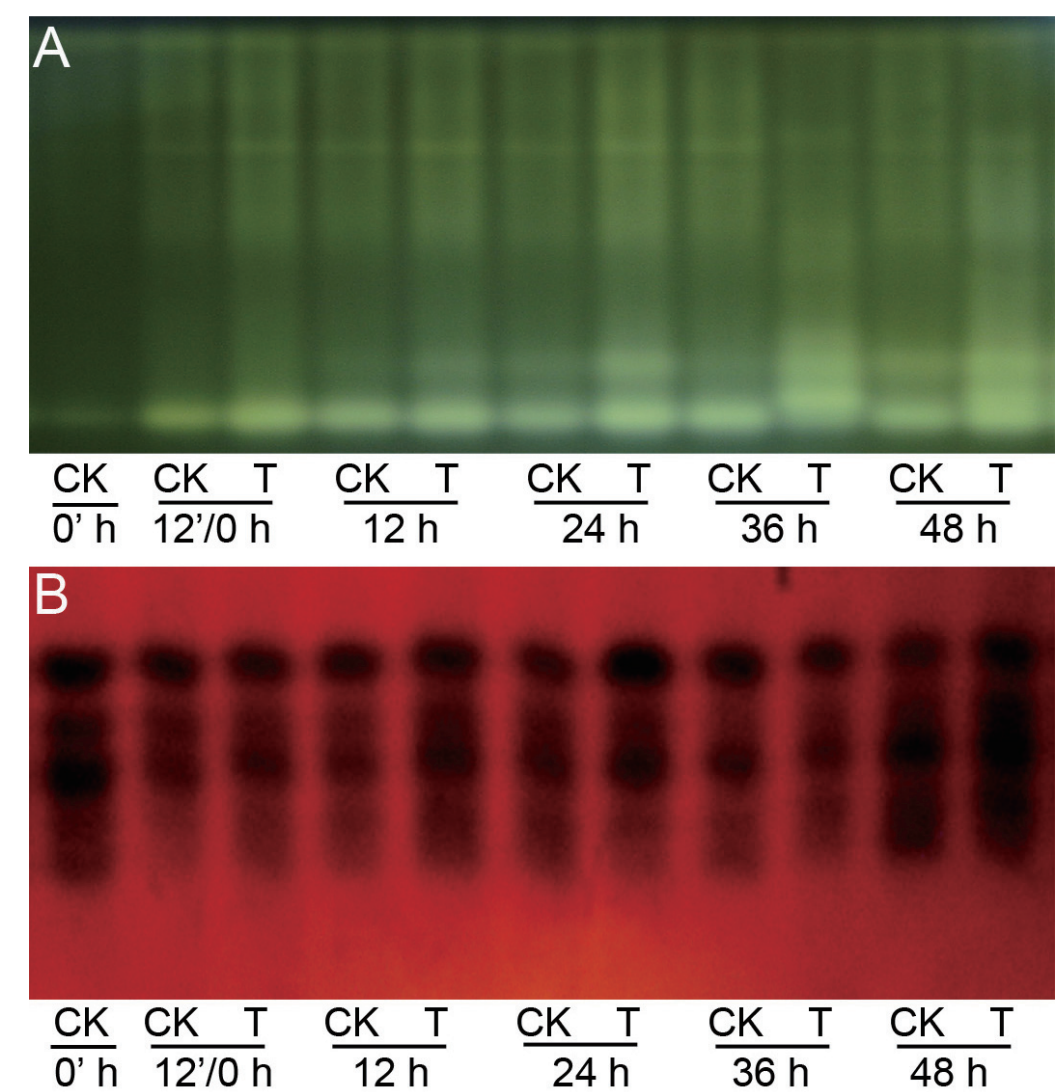

Figure 1. Changes of amylase and esterase activities in salinity-stressed wheat grain pretreated with water as control or $1.2 \mathrm{mM} \mathrm{NaHS}$ for $12 \mathrm{~h}$

(A) Native polyacrylamide gel electrophoresis (PAGE) of amylase in wheat grain pretreated with water as control (CK) or $1.2 \mathrm{mM} \mathrm{NaHS}$ for $12 \mathrm{~h}$ (shown as from $0^{\prime} \mathrm{h}$ to $12^{\prime} / 0 \mathrm{~h}$ of the pretreatment time) prior to $0.16 \mathrm{M} \mathrm{NaCl}$ stress for further $48 \mathrm{~h}$ (shown as $0,12,24,36,48 \mathrm{~h}$, respectively)

(B) Native polyacrylamide gel electrophoresis of esterase in wheat grain. The indicated time points are the same to Figure $1 \mathrm{~A}$ 
Figure 1B shows the changes of esterase activity in $\mathrm{NaCl}$-stressed wheat grain with water or NaHS pretreatment. NaHS pretreatment could maintain higher esterase activities than water control especially at $12 \mathrm{~h}, 24 \mathrm{~h}$ and $48 \mathrm{~h}$ of salt stress. The above results suggested the role of $\mathrm{H}_{2} \mathrm{~S}$ in improving the activities of secreted hydrolases in germinating wheat grain under $\mathrm{NaCl}$ stress.

Effect of NaHS pretreatment on the activities of antioxidant enzymes in $\mathrm{NaCl}$-stressed wheat grain

To further study the protective role of $\mathrm{H}_{2} \mathrm{~S}$ on $\mathrm{NaCl}$-stressed grain, activities of antioxidant enzymes were determined with time in NaHS-pretreated grain and controls. Figure 2A illustrates the changes of CAT activity in both treatments. During the pretreatment time, a higher level of CAT activity was observed in water controls than in NaHS-pretreated grain. Thereafter, CAT activity in water pretreated grain decreased gradually until $36 \mathrm{~h}$, whereas that of NaHS pretreatment increased continuously. At $48 \mathrm{~h}$, an obvious increase occurred in both treatments. After $\mathrm{NaCl}$ stress for $36 \mathrm{~h}$, CAT activity of NaHS-pretreated grain was significantly higher than that of water controls.

Figure $2 \mathrm{~B}$ shows that during the pretreatment time, APX activity showed a significant increase in both NaHS pretreatment and water control. Then APX activity in water-pretreated grain kept a relative stable level till $48 \mathrm{~h}$ of $\mathrm{NaCl}$ stress, whereas that of NaHS pretreatment increased steadily and peaked at $24 \mathrm{~h}$ followed by an obvious decrease. At 24 and $48 \mathrm{~h}$ of $\mathrm{NaCl}$ stress, NaHS pretreatment sustained significantly higher level of APX activity than water control.

Figure $2 \mathrm{C}$ illustrates the changes of POD activity in both treatments. During pretreatment time and the first $24 \mathrm{~h}$ of $\mathrm{NaCl}$ stress, POD activity in water-pretreated control decreased continually and maintained a relatively stable level thereafter. However, POD activity in NaHS-pretreated grain kept stable through the pretreatment time and the first $12 \mathrm{~h}$ of $\mathrm{NaCl}$ stress. Then the activity in NaHS-pretreated grain increased steadily to a maximum at $48 \mathrm{~h}$. During the entire treatment time, POD activity in NaHS-pretreated grain was maintained at a much higher level than that of water controls.

\section{Effect of $\mathrm{H}_{2} \mathrm{~S}$ donor NaHS on MDA content in grain and plasma membrane integrity} in radicle tips

To estimate membrane lipid breakdown, the content of malondialdehyde (MDA) was determined in wheat grain with treatment time. As illustrated in Figure 3A, MDA content in both NaHS pretreatment and control decreased gradually over the whole duration, except an MDA burst occurred in water controls after exposure to $\mathrm{NaCl}$ for $12 \mathrm{~h}$. NaHS pretreatment significantly reduced the accumulation of MDA at $12 \mathrm{~h}$ of $\mathrm{NaCl}$ stress in wheat grain in contrast to water pretreatment.

Radicle tips from grains of each treatment were stained with Evans blue to detect the effect of $\mathrm{H}_{2} \mathrm{~S}$ on plasma membrane permeability in $\mathrm{NaCl}$-stressed wheat radicles. There was no obvious difference between NaHS-treatment and water control (Fig. 3B), suggesting that $1.2 \mathrm{mM}$ NaHS showed no negative effect to radicle membrane integrity. However, after exposure to $\mathrm{NaCl}$ stress, NaHS-pretreatment showed less staining intensity, indicating 

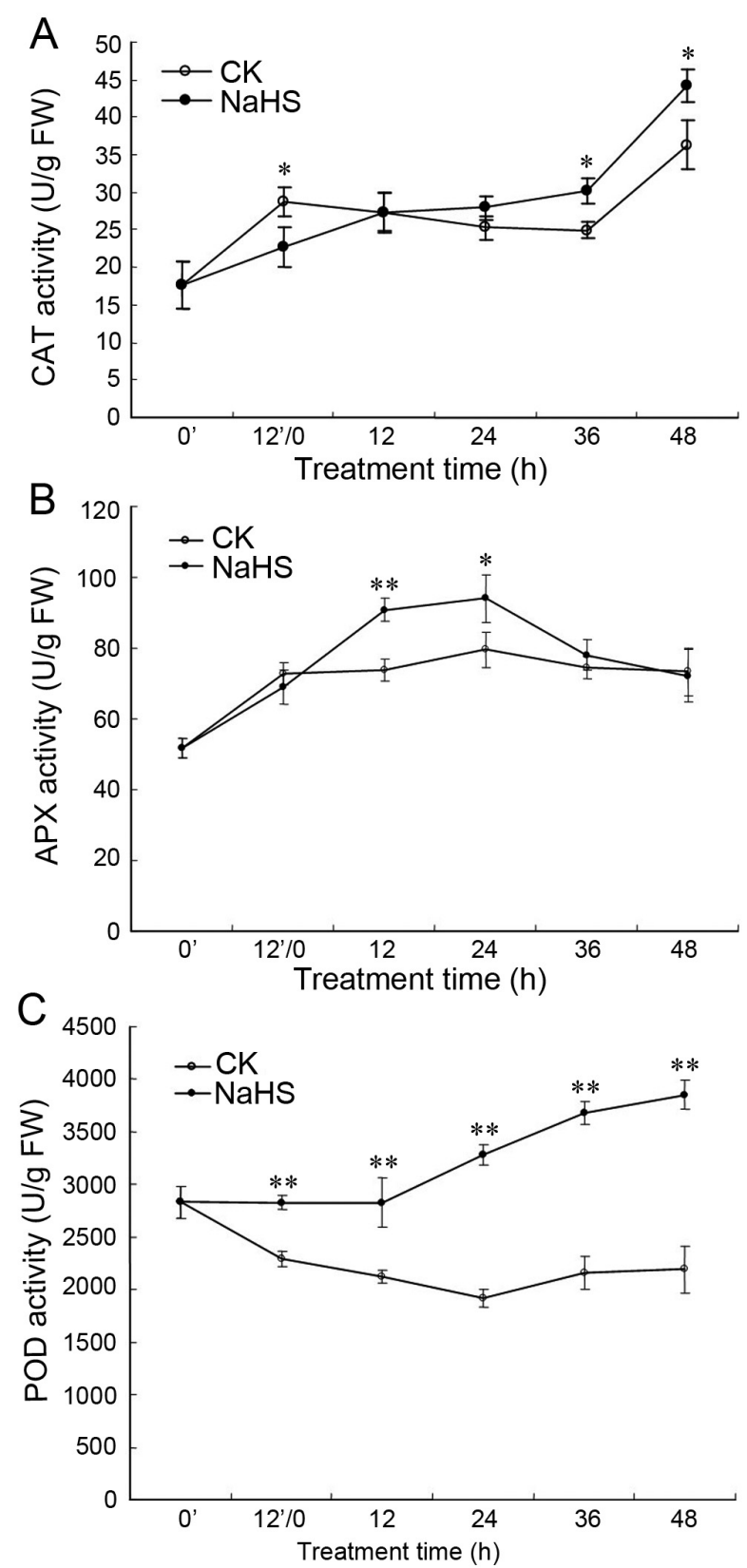

Figure 2. Effect of NaHS pretreatment on the activities of catalase (CAT) (A), ascorbate peroxidase (APX) (B), and peroxidase (POD) (C) in germinating wheat grain under $0.16 \mathrm{M} \mathrm{NaCl}$ stress. Wheat grain were pretreated with water (CK) or NaHS (NaHS) for $12 \mathrm{~h}$ (shown as from $0^{\prime} \mathrm{h}$ to $12^{\prime} / 0 \mathrm{~h}$ ) and further treated with $1.2 \mathrm{mM} \mathrm{NaCl}$ for $12,24,36,48 \mathrm{~h}$, respectively 


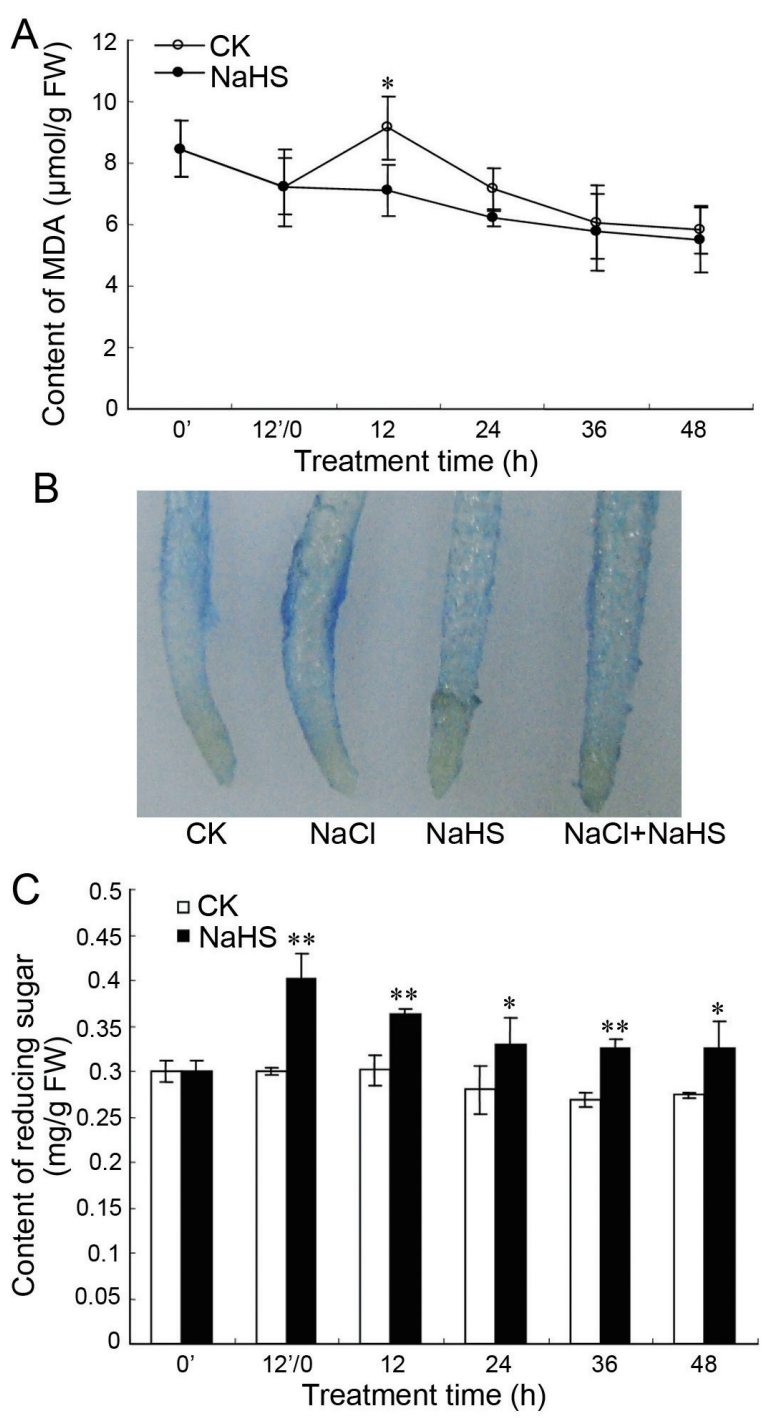

Figure 3. Effects of NaHS pretreatment on the content of malondialdehyde (MDA) (A), plasma membrane integrity $(\mathrm{B})$ and reducing sugar $(\mathrm{C})$ in wheat grain under $\mathrm{NaCl}$ stress.

The time points $\left(0^{\prime} \mathrm{h}, 12^{\prime} / 0 \mathrm{~h}, 12 \mathrm{~h}, 24 \mathrm{~h}, 36 \mathrm{~h}, 48 \mathrm{~h}\right)$ represented as the same mentioned in Fig. 2

For the plasma membrane integrity in radicle tips (B), intact wheat grain were cultured in water for $72 \mathrm{~h}(\mathrm{CK})$. For $\mathrm{NaCl}$ stress $(\mathrm{NaCl})$, wheat grain were cultured in water for $36 \mathrm{~h}$, then subjected to $0.16 \mathrm{M} \mathrm{NaCl}$ for further $36 \mathrm{~h}$. Grain were cultured in water for $24 \mathrm{~h}$ and immersed in $1.2 \mathrm{mM} \mathrm{NaHS}$ for $12 \mathrm{~h}$, then divided into two equal groups and transferred to water (NaHS) or $0.16 \mathrm{M} \mathrm{NaCl}$ stress $(\mathrm{NaCl}+\mathrm{NaHS})$ for $36 \mathrm{~h}$, respectively. Then the radicle tips (about $2 \mathrm{~cm}$ ) were sampled for Evans blue staining to analyze plasma membrane integrity. (C) shows effect of NaHS pretreatment on the content of reducing sugar in wheat grain under $\mathrm{NaCl}$ stress. The time points $\left(0^{\prime} \mathrm{h}, 12^{\prime} / 0 \mathrm{~h}, 12 \mathrm{~h}, 24 \mathrm{~h}, 36 \mathrm{~h}, 48 \mathrm{~h}\right)$ represented as the same mentioned in Fig. 2 
less plasma membrane damage compared to pure $\mathrm{NaCl}$ stress. These results indicated that $\mathrm{H}_{2} \mathrm{~S}$ apparently alleviated membrane damage induced by $\mathrm{NaCl}$ stress.

\section{Effect of $\mathrm{H}_{2} \mathrm{~S}$ donor NaHS on reducing sugar contents in grain}

Sugars that contain aldehyde groups are classified as reducing sugars. Figure $3 \mathrm{C}$ shows that after $12 \mathrm{~h}$ of pretreatment time, reducing sugar contents in NaHS-pretreated grain showed a significant increase, while that of water control was maintained at a stable level equal to that of dry grain. After exposure to the $\mathrm{NaCl}$ stress, contents of reducing sugar decreased slightly in both treatments until $48 \mathrm{~h}$. During entire treatment time, reducing sugar content in NaHS-pretreated grain was maintained at a significantly higher level than that of water controls.

\section{Discussion}

A high concentration of salt in the soil is known to be injurious to plant growth and may lead to three major types of stress, namely ionic, osmotic, and oxidative stress (Zhu 2002). The results reported in this paper show clearly that $\mathrm{NaCl}$ inhibits wheat grain germination and retards coleoptile and radicle growth. Similar trends have been found in several plant species subjected to salinity stress (Wang et al. 2012). The novel aspect of our work is that pretreatment of wheat grains with $\mathrm{NaHS}$ as an exogenous $\mathrm{H}_{2} \mathrm{~S}$ donor for $12 \mathrm{~h}$ could alleviate subsequent salinity stress, suggesting a potential strategy of NaHS application in mitigating salinity stress in wheat.

$\mathrm{H}_{2} \mathrm{~S}$ had been known for centuries as a potentially toxic gas. In recent years, accumulating evidence has demonstrated that $\mathrm{H}_{2} \mathrm{~S}$ acts as a signaling molecule in animals (Wang 2012). It has now been shown that $\mathrm{H}_{2} \mathrm{~S}$ can be formed endogenously in plants from sulfite or cysteine by the actions of sulfite reductase and desulfhydrases, respectively (Rausch and Wachter 2005). Given the fact that $\mathrm{H}_{2} \mathrm{~S}$ is endogenously produced in plants, it is important to examine its potential physiological roles. Recently, $\mathrm{H}_{2} \mathrm{~S}$ was shown to participate in abiotic stress resistance (Zhang et al. 2008, 2010; Jin et al. 2011, 2013), in plant defense against pathogen attack (Bloem et al. 2004), stomatal movement (García-Mata and Lamattina 2010; Lisjak et al. 2010), adventitious root organogenesis (Zhang et al. 2009), and autophagy (Ailvarez et al. 2012). In our present study, pretreatment with $1.2 \mathrm{mM}$ $\mathrm{NaHS}$ for $12 \mathrm{~h}$ significantly improved wheat grain germination under $\mathrm{NaCl}$ stress. Starch endosperm and esters are the major part of wheat grain, so their mobilization by amylase and esterase is essential for wheat grain germination. NaHS pretreatment enabled higher activities of amylase and esterase in $\mathrm{NaCl}$-stressed wheat grain compared with water pretreatment controls (Fig. 1). In NaHS-pretreated grain, the content of reducing sugar was higher than that of control, indicating that higher amylase activity induced by $\mathrm{H}_{2} \mathrm{~S}$ could stimulate the mobilization of starch reservoir in wheat grain.

Overproduction of ROS, i.e. superoxide radical, hydrogen peroxide, singlet oxygen and hydroxyl radical is an important consequence of salinity stress (Zhu 2002; Leshem et al. 2007). To cope with ROS accumulation, plants mobilize antioxidant enzymes such as superoxide dismutase (SOD), catalase (CAT) and ascorbate peroxidase (APX) to scav- 
enge ROS and avoid oxidative damage (Sekmen et al. 2007). In our present study, salinity treatment resulted in MDA overproduction at $12 \mathrm{~h}$ of $\mathrm{NaCl}$ stress, suggesting that oxidative stress induced by salinity contributed to excessive lipid peroxidation. In contrast, NaHS pretreatment significantly reduced the accumulation of MDA (Fig. 3A). Evans blue staining indicated that $\mathrm{H}_{2} \mathrm{~S}$ could serve to protect against $\mathrm{NaCl}$-induced loss of plasma membrane integrity in the radicle tips (Fig. 3B). To further understand the protective role of $\mathrm{H}_{2} \mathrm{~S}$ to wheat grain under salt stress, we examined the activities of several antioxidant enzymes. We observed that NaHS pretreatment generally enhanced CAT, APX, POD activities in wheat grain under $\mathrm{NaCl}$ stress. The increase in ROS scavenging enzymes may help to alleviate lipid oxidation as shown by much lower amounts of MDA content in NaHS-pretreated wheat. Taken together, this data strongly supports the idea that $\mathrm{H}_{2} \mathrm{~S}$ promotes wheat grain germination under salt stress by activating antioxidant system. Consistent to our study, $\mathrm{H}_{2} \mathrm{~S}$ has been implicated in antioxidant activation in many plants subjected to various stresses (Zhang et al. 2008, 2010; Jin et al. 2011, 2013; Christou et al. 2013). Besides, we previously show that concentrations of NaHS up to $1.4 \mathrm{mM}$ showed no negative effect on wheat germination, suggesting role of $\mathrm{H}_{2} \mathrm{~S}$ is not due to cross-tolerance (Zhang et al. 2008).

Our evidence adds to the concept that $\mathrm{H}_{2} \mathrm{~S}$ acts as an important signal molecule in abiotic stress tolerance. NaHS pretreatment could significantly promote the germination percentage and root growth, enhance the activities of amylase and esterase and the content of reducing sugar and ameliorate the $\mathrm{NaCl}$-induced damage of plasma membrane integrity. Meanwhile, increase in the activities of CAT, POD and APX suggested that $\mathrm{H}_{2} \mathrm{~S}$ exerted its protective effect through the activation of some antioxidant enzymes. However, the underlying mechanism of $\mathrm{H}_{2} \mathrm{~S}$ as a signal molecule is still obscure. Similar to the mechanism that NO physiologically S-nitrosylates diverse proteins, in animals, endogenous $\mathrm{H}_{2} \mathrm{~S}$ was found to regulate proteins through protein S-sulfhydration (that is, converts cysteine-SH groups to -SSH) (Mustafa et al. 2009). Thus, research of protein modification by $\mathrm{H}_{2} \mathrm{~S}$ might help to improve our understanding of the functional mechanisms of $\mathrm{H}_{2} \mathrm{~S}$.

\section{Acknowledgements}

We are grateful to Russell Jones, University of California at Berkeley for critical reading the manuscript. This work was supported by the Natural Science Foundation of China (31271803, 31301820, 31470013, 31300133), the Scientific Research Foundation for the Returned Overseas Chinese Scholars (SRF for ROCS, SEM), the Natural Science Foundations of Anhui Province (11040606M85) and the Anhui Provincial Education Department (2012AJZR0028, ZD200910).

\section{References}

Álvarez, C., García, I., Moreno, I., Pérez-Pérez, M.E., Crespo, J.L., Romero, L.C., Gotor, C. 2012. Cysteine-generated sulfide in the cytosol negatively regulates autophagy and modulates the transcriptional profile in Arabidopsis. Plant Cell 24:4621-4634.

Cereal Research Communications 43, 2015 
Bloem, E., Haneklaus, S., Schnug, E. 2005. Significance of sulfur compounds in the protection of plants against pests and diseases. J. Plant Nutr. 28:763-784.

Bloem, E., Riemenschneider, A., Volker, J., Papenbrock, J., Schmidt, A., Salac, I., Haneklaus, S., Schnug, E. 2004. Sulphur supply and infection with Pyrenopeziza brassicae influence L-cysteine desulphydrase activity in Brassica napus L. J. Exp. Bot. 55:2305-2312.

Christou, A., Manganaris, G.A., Papadopoulos, I., Fotopoulos, V. 2013. Hydrogen sulfide induces systemic tolerance to salinity and non-ionic osmotic stress in strawberry plants through modification of reactive species biosynthesis and transcriptional regulation of multiple defence pathways. J. Exp. Bot. 64:1953-1966.

Deising, H., Nicholson, R.L., Haug, M., Howard, R.J., Mendgen, K. 1992. Adhesion pad formation and the involvement of cutinase and esterases in the attachment of uredospores to the host cuticle. Plant Cell 4:1101-1111.

Gao, S.P., Hu, K.D., Hu, L.Y., Li, Y.H., Han, Y., Wang, H.L., Lv, K., Liu, Y.S., Zhang, H. 2013. Hydrogen sulfide delays postharvest senescence and plays an antioxidative role in fresh-cut kiwifruit. HortScience 48:1385-1392.

García-Limones, C., Hervás, A., Navas-Cortés, J.A., Jiménez-Díaz, R.M., Tena, M. 2002. Induction of an antioxidant enzyme system and other oxidative stress markers associated with compatible and incompatible interactions between chickpea (Cicer arietinum L.) and Fusarium oxysporum f. sp. ciceris. Physiol. Mol. Plant Pathol. 61:325-337.

García-Mata, C., Lamattina, L. 2010. Hydrogen sulphide, a novel gasotransmitter involved in guard cell signalling. New Phytol. 188:977-984.

Hu, L.Y., Hu, S.L., Wu, J., Li, Y.H., Zheng, J.L., Wei, Z.J., Liu, J., Wang, H.L., Liu, Y.S., Zhang, H. 2012. Hydrogen sulfide prolongs postharvest shelf life of strawberry and plays an antioxidative role in fruits. J. Agric. Food Chem. 60:8684-8693.

Jin, Z., Shen, J., Qiao, Z., Yang, G., Wang, R., Pei, Y. 2011. Hydrogen sulfide improves drought resistance in Arabidopsis thaliana. Biochem. Biophys. Res. Commun. 414:481-486.

Jin, Z., Xue, S., Luo, Y., Tian, B., Fang, H., Li, H., Pei, Y. 2013. Hydrogen sulfide interacting with abscisic acid in stomatal regulation responses to drought stress in Arabidopsis. Plant Physiol. Biochem. 62:41-46.

Leshem, Y., Seri, L., Levine, A. 2007. Induction of phosphatidylinositol 3-kinase-mediated endocytosis by salt stress leads to intracellular production of reactive oxygen species and salt tolerance. Plant J. 51:185-197.

Lisjak, M., Srivastava, N., Teklic, T., Civale, L., Lewandowski, K., Wilson, I., Wood, M.E., Whiteman, M., Hancock, J.T. 2010. A novel hydrogen sulfide donor causes stomatal opening and reduces nitric oxide accumulation. Plant Physiol. Biochem. 48:931-935.

Lisjak, M., Teklic, T., Wilson, I.D., Whiteman, M., Hancock, J.T. 2013. Hydrogen sulfide: Environmental factor or signalling molecule? Plant Cell Environ. 36:1607-1616.

Mustafa, A.K., Gadalla, M.M., Sen, N., Kim, S., Mu, W., Gazi, S.K., Barrow, R.K., Yang, G., Wang, R., Snyder, S.H. 2009. $\mathrm{H}_{2} \mathrm{~S}$ signals through protein S-sulfhydration. Sci. Signal 2:ra72.

Rausch, T., Wachter, A. 2005. Sulfur metabolism: A versatile platform for launching defence operations. Trends Plant Sci. 10:503-509.

Sekmen, A.H., Türkan, I., Takio, S. 2007. Differential responses of antioxidative enzymes and lipid peroxidation to salt stress in salt-tolerant Plantago maritima and salt-sensitive Plantago media. Physiol. Plant. 131:399-411.

Wang, R. 2012. Physiological implications of hydrogen sulfide: A whiff exploration that blossomed. Physiol Rev. 92:791-896.

Wang, Y., Li, L., Cui, W., Xu, S., Shen, W., Wang, R. 2012. Hydrogen sulfide enhances alfalfa (Medicago sativa) tolerance against salinity during seed germination by nitric oxide pathway. Plant Soil 351:107-119.

Wang, Y.S., Yang, Z.M. 2005. Nitric oxide reduces aluminum toxicity by preventing oxidative stress in the roots of Cassia tora L. Plant Cell Physiol. 46:1915-1923.

Yamamoto, Y., Kobayashi, Y., Matsumoto, H. 2001. Lipid peroxidation is an early symptom triggered by aluminum, but not the primary cause of elongation inhibition in pea roots. Plant Physiol. 125:199-208.

Yang, G., Wu, L., Jiang, B., Yang, W., Qi, J., Cao, K., Meng, Q., Mustafa, A.K., Mu, W., Zhang, S., Snyder, S.H., Wang, R. 2008. $\mathrm{H}_{2} \mathrm{~S}$ as a physiologic vasorelaxant: hypertension in mice with deletion of cystathionine gamma-lyase. Science 322:587-590.

Zhang, H., Shen, W.B., Zhang, W., Xu, L.L. 2005. A rapid response of $\alpha$-amylase to nitric oxide but not gibberellin in wheat seeds during the early stage of germination. Planta 220:708-716.

Cereal Research Communications 43, 2015 
Zhang, H., Hu, L.Y., Hu, K.D., He, Y.D., Wang, S.H., Luo, J.P. 2008. Hydrogen sulfide promotes wheat seed germination and alleviates oxidative damage against copper stress. J. Integr. Plant Biol. 50:1518-1529.

Zhang, H., Tang, J., Liu, X.P., Wang, Y., Yu, W., Peng, W.Y., Fang, F., Ma, D.F., Wei, Z.J., Hu, L.Y. 2009. Hydrogen sulfide promotes root organogenesis in Ipomoea batatas, Salix matsudana, and Glycine max, J. Integr. Plant Biol. 51:1086-1094.

Zhang, H., Tan, Z.Q., Hu, L.Y., Wang, S.H., Luo, J.P., Jones, R.L. 2010. Hydrogen sulfide alleviates aluminum toxicity in germinating wheat seedlings. J. Integr. Plant Biol. 52:556-567.

Zhang, H., Hu, S.L., Zhang, Z.J., Hu, L.Y., Jiang, C.X., Wei, Z.J., Liu, J., Wang, H.L., Jiang, S.T. 2011. Hydrogen sulfide acts as a regulator of flower senescence in plants. Postharvest Biol. Technol. 60:251-257.

Zhu, J.K. 2001. Plant salt tolerance. Trends Plant Sci. 6:66-71.

Zhu, J.K. 2002. Salt and drought stress signal transduction in plants. Annu. Rev. Plant Biol. 53:247-273.

\section{Electronic Supplementary Material (ESM)}

Electronic Supplementary Material (ESM) associated with this article can be found at the website of CRC at http://www.akademiai.com/content/120427/

Electronic Supplementary Table S1. Inhibitory effect of $\mathrm{NaCl}$ on wheat grain germination

Electronic Supplementary Figure S1. Inhibitory effect of $\mathrm{NaCl}$ stress on wheat grain germination. Wheat grain were cultured under $0.00,0.08,0.16,0.24,0.32$ and $0.40 \mathrm{M} \mathrm{NaCl}$ stress for $72 \mathrm{~h}$, then photographed

Electronic Supplementary Figure $\mathrm{S} 2 . \mathrm{H}_{2} \mathrm{~S}$ donor NaHS promoted wheat grain germination under $\mathrm{NaCl}$ stress. Wheat grain were pretreated with $0.0,0.6,1.2,1.8,2.4,3.0 \mathrm{mM} \mathrm{NaHS}$, respectively, for $10 \mathrm{~h}$, and subsequently subjected to $0.16 \mathrm{M} \mathrm{NaCl}$ stress for further $48 \mathrm{~h}$, then photographed 